\title{
EDITORIAL
}

\section{Rückbesinnung auf den Staat}

\author{
Torsten Brandt, Thorsten Schulten, Astrid Ziegler
}

Im November 2008 veranstaltete das Wirtschafts- und Sozialwissenschaftliche Institut in der Hans-Böckler-Stiftung das WSIHerbstforum mit dem Titel „Die Rückkehr des Staates“. Dieses Schwerpunktheft dokumentiert ausgewählte Beiträge und führt die Diskussion fort.

Als wir Anfang 2008 mit der thematischen Planung des Herbstforums begannen, verdichteten sich zwar die Probleme, die mit dem Rückzug staatlichen Engagements verbunden sind, der politische Diskurs wurde aber von Stimmen dominiert, denen der Abbau des Staates immer noch nicht weit genug ging. Im Herbst 2008 wurde deutlich sichtbar, dass sich mit dem Ausbruch der internationalen Finanzkrise das politische Denken über die Rolle des Staates grundlegend wandeln würde. Die Rückkehr des Staates war nun in aller Munde. Der Staat sollte der angeschlagenen Finanzwirtschaft mit Milliardenbeträgen auf die Sprünge helfen und gleichzeitig die drohende weltwirtschaftliche Rezession bekämpfen. Laut Meinungsumfragen wurden die staatliche Beteiligung an Schlüsselindustrien und insbesondere die Verstaatlichung des Banken- und Elektrizitätssektors populär. Die französische Regierung plädierte gar für die Schaffung eines Staatsfonds, der sich an den wichtigsten Schlüsselindustrien in Frankreich beteiligen sollte.

Heute wird das Übergreifen der Finanzkrise auf Realwirtschaft und Arbeitsmärkte immer akuter. Nachdem die internationalen Finanzmärkte fürs Erste dank öffentlicher Mittel vor dem Kollaps bewahrt wurden, versucht der Staat in vielen Ländern, mit historisch bislang einzigartigen Konjunkturpaketen der Weltwirtschaftskrise entgegenzusteuern. In Deutschland fallen die Konjunkturpakete jedoch vergleichsweise bescheiden aus und der öffentliche Diskurs verändert sich erneut. So zeigt sich in der Diskussion um die Finanzhilfen für Opel oder Schaeffler, dass es im realwirtschaftlichen Bereich - anders als bei der Bankenkrise - nicht um eine vorbehaltlose Rückkehr des (Kriseninterventions-)Staates geht, sondern eher um eine abwägende Rückbesinnung auf die Aufgaben des Staates: Welche Rolle hat er in welchen Bereichen zu spielen und welche nicht? Wo und wie soll der Staat aktiver werden? Brauchen wir ein neues Leitbild über die Rolle des Staates und wie könnte dieses aussehen?

Klar ist, dass es heute unter veränderten Rahmenbedingungen nicht einfach um eine Rückkehr zum Modell des ,keynesianischen Wohlfahrtsstaates" der Nachkriegsperiode geht, der über ideologische Differenzen hinweg oft auch als träge, Autonomie gefährdend und undemokratisch wahrgenommen wurde. Auch heutzutage wird ein Demokratiedefizit beklagt, wenngleich dabei zumeist auf die Europäischen Union abgestellt wird. Sie ist zu einem wichtigen Akteur eines neoliberalen Gesellschaftsprojektes geworden, dessen politische Essenz sich in der Trias von Deregulierung, Liberalisierung und Privatisierung zusammenfassen lässt
- mit der Folge einer grundlegenden Änderung im Staatsverständnis: Das neue Ziel bestand darin, als ,,schlanker Staat“ möglichst wenig direkt in die Wirtschaft einzugreifen und ein weitestgehend ungehindertes Wirken der Marktmechanismen sicherzustellen. Dem entspricht das - trotz zunehmender Privatisierungsund Liberalisierungskritik - immer noch existierende Leitbild des "Gewährleistungsstaates“, wonach der Staat die Erbringung öffentlicher Aufgaben privaten Akteuren überlässt und dabei selbst für das Gemeinwohl sichernde Regelungsstrukturen sorgen will.

Mit Peter Bofinger ist aber festzustellen, dass Deutschland in den letzten Jahren einen im internationalen Vergleich einzigartigen Schwund staatlichen Einflusses erlebt hat. Dadurch sind notwendige Zukunftsinvestitionen ausgeblieben und Defizite der öffentlichen Daseinsvorsorge aufgetreten. Folglich sei der Staat nach dem durchlaufenen ,Jahrzehnt der Entstaatlichung“ finanziell und politisch nur noch begrenzt in der Lage, für eine Gewährleistung öffentlicher Aufgaben zu sorgen. Es gibt jedoch gute Gründe dafür, auch sehr ehrgeizige Investitionspläne öffentlich zu finanzieren, ohne dass es dazu einer Einschränkung des Sozialstaates bedarf. Denn die Staatsfinanzierung bleibt im Wesentlichen ein politisches und kein ökonomisches Problem. Für das Gemeinwohl entscheidend ist dabei, ob staatliche Hilfe und Strukturförderung an die Einhaltung sozialer Bedingungen geknüpft werden.

Die aktuelle Krise hat ein Zeitfenster geöffnet, das es erlaubt, grundlegend neu über die Rolle des Staates nachzudenken. Die in diesem Schwerpunktheft versammelten Beiträge sehen die zentrale Aufgabe des Staates darin, für mehr soziale Gerechtigkeit zu sorgen und die wachsende Ungleichverteilung von Ressourcen in der Gesellschaft zu verringern. Das bedeutet, allen Bürgern flächendeckend günstige oder kostenlose Dienstleistungen zur Verfügung zu stellen, qualitativ und tariflich abgesicherte Beschäftigung zu schaffen, Zukunftsinvestitionen zu sichern und demokratische Einflussmöglichkeiten auszubauen.

\footnotetext{
Konzept und Koordination des Schwerpunkthefts: Torsten Brandt, Wissenschaftler im WSI in der Hans-Böckler-Stiftung (Projekt PIQUE). Arbeitsschwerpunkte: Privatisierung öffentlicher Dienstleistungen, Arbeitsmarktpolitik, Industrielle Beziehungen in Europa. e-mail: Torsten-Brandt@boeckler.de Thorsten Schulten, Dr., Wissenschaftler im WSI in der Hans-BöcklerStiftung. Arbeitsschwerpunkte: Arbeits- und Tarifpolitik in Europa. e-mail: Thorsten-Schulten@boeckler.de

Astrid Ziegler, Dr., Wissenschaftlerin im WSI in der Hans-Böckler-Stiftung. Arbeitsschwerpunkt: Strukturforschung und -politik. e-mail: Astrid-Ziegler@boeckler.de
} 